\title{
The Performance of Daylight through Various Windows for Residential Buildings
}

\author{
Sharifah Nor Fairuz Syed Husin, Zarina Yasmin Hanur Harith \\ Faculty of Architecture, Planning and Surveying, \\ Universiti Teknologi MARA Shah Alam, Selangor, Malaysia \\ snfsh@ymail.com
}

\begin{abstract}
A good daylighting strategy is necessary in order to decrease energy consumption for artificial lighting. To provide effective internal illumination, the placing of the right openings in the right positions with suitable type of window and glazing is important. This study focused on the various types and materials of the glass and window, in order to identify the quantity and quality of daylight that penetrate into the residential buildings. Based on a series of measurement, it was identified that type of glazing and window gives major significance on the performance of daylight and thermal performance in residential buildings.
\end{abstract}

Keywords windows; illumination level; residential building; occupant's perception.

eISSN 2514-751X @ 2018. The Authors. Published for AMER ABRA cE-Bs by e-International Publishing House, Ltd., UK. This is an open-access article under the CC BY-NC-ND license (http://creativecommons.org/licenses/bync-nd/4.0/). Peer-review under responsibility of AMER (Association of Malaysian Environment-Behaviour Researchers), ABRA (Association of Behavioural Researchers on Asians) and cE-Bs (Centre for EnvironmentBehaviour Studies), Faculty of Architecture, Planning \& Surveying, Universiti Teknologi MARA, Malaysia.

DOI: https://doi.org/10.21834/aje-bs.v3i6.247 


\subsection{Introduction}

Daylight is a source which can save the energy and able to create a pleasant visual environment for occupants. According to Illuminating Engineering Society of North America (IESNA, daylighting is a technique to bring natural light into a room by manipulating this free resources to achieve required illumination level in that room. By having a good daylighting strategy, it helps to create a visually stimulating and productive environment for building occupants. Li et al., (2006 believe that the performance of daylight entering into the area depends on some of the internal environment (size and position of the windows, the depth and shape of the rooms and the colours of the internal surface and external factors (light reflected from the ground and opposite obstruction. This study is focused on the internal factor which is size and position of the windows only. The performance of natural light that penetrate through various size and position of fenestration need to be investigated, in order to make sure that enough amount of daylight is received without creating any undesirable effects to occupied space. Typical residential buildings in Malaysia usually use windows as their common important fenestration. This is to allow natural daylight transmits into the interior of the building and allows occupant to maintain visual contact with the outside view. Size and position of the window can have major impact of the efficient use of daylighting and therefore reduce the electric consumption for artificial lighting. This paper studies the daylighting performance through typical types of window fenestration in residential building which are casement with obscure glass window (CWOGW, fixed louver with clear glass window (FLWCGW and adjusted louver with tinted glass window (ALWTGW . Simple on-site measurements were done to identify the level of illuminance by using straight line points along the central of the window. Measured illuminance levels were then analysed to determine the depth and quantity of daylight (daylighting performance penetrated into the residential buildings particularly in the living area.

\subsection{Factor Affecting Daylighting Performance Building orientations}

A proper orientation of the building is the major factor which affects the performance of daylight penetration. Due to the movement of the sun in Malaysia, layout of the building must be on east-west axis with the major windows facing either north or south in order to maximise penetration of daylight. SIRIM (2006 recognised that direct sunlight easily transmit and result to the increasing building energy consumption by $20 \%$ or more when windows facing to the east or west.

\section{1,2 Type of windows}

Windows have a bigger impact on the quantity of daylight penetration. The most common type of windows that are identified used in residential building in Malaysia are casement windows and louver windows. Casement window is able to provide excellent ventilation and if they seal tightly when closed, it can still allow penetration of natural light. These windows consist of glass as the main material.

Casement windows are widely used in Malaysia because of their capacity to let in light and fresh air. Louver windows have horizontal or vertical slats which can be angled to admit light and air into the interior space. The angle of the slats can be adjustable. Many houses 
used this type of window because it can improve indoor daylighting and limit glare or redirect diffuse light.

\subsection{Type of glass}

he glass used for windows in building provides light and allow vision. Different type of glass have different energy-performance characteristic. That is the ability to resist heat transfer (Uvalue;UV, ability to control solar heat gain through the glazing (Solar Heat Gain Coefficien;SHGC and the amount of light passes through a glazing material (visible transmittance;VT . By knowing the amount of UV, SHGC and VT of the window, it helps user to select the right window in order to maximise daylight effectiveness and occupant's comfort.

Typical glazing windows that are widely used in residentialbuilding are clear glass, obscure glass and tinted glass. Clear single glazing is able to permit highest daylight transmission and allows heat loss or heat gain depending on climate condition. Table 1 indicate UV, SHGC and VT of clear single glazing using different type of frame. Tinted glass refers to any glass that has been treated with a material such as a film or coating, which reduces the transmission of light through it and helps in energy efficiency and conservation. According to Carmody (2000, the main uses of this glass are to reduce glare and solar energy transmitted to the interior. Tinted glass window also makes the temperature inside the room cooler. Table 2 shows the whole window properties for tinted glazing using different frames. Ibrahim and Zain-Ahmed (200T found that the maximum depth for clear and tinted glass with a maximum window height of $3 \mathrm{~m}$ to be fully day-lit is $4 \mathrm{~m}$. Obscure glasses are able to transmit natural light and at the same time can break up the view in order to offer privacy or safety. The effect is generally achieved either with decorative embossed pattern or with a frosted surface that scatters the light rays.

Table 1: Whole Window Properties for Different Frames Using Clear Single Glass

\begin{tabular}{|l|c|c|r|}
\hline Frame Type & U-Value & SHGC & VT \\
\hline Aluminium & 1.25 & $0 . T 6$ & $0 . T 4$ \\
\hline Aluminium with thermal break & 1.08 & $0 . T 0$ & 0.69 \\
\hline Wood or wood-clad & 0.90 & 0.63 & 0.64 \\
\hline Vinyl or wood/vinyl hybrid & 0.90 & 0.63 & 0.64 \\
\hline Insulated vinyl or fibreglass & - & - & - \\
\hline
\end{tabular}

Source: (Carmody et al., 2000)

Table2: WholeWindowPropertiesforDifferentFramesUsingSingleGlass with Bronze or Gray Tint

\begin{tabular}{|l|c|c|l|}
\hline Frame Type & U-Value & SHGC & VT \\
\hline Aluminium & 1.25 & 0.65 & 0.56 \\
\hline Aluminium with thermal break & 1.08 & 0.60 & 0.52 \\
\hline Wood or wood-clad & 0.90 & 0.54 & 0.48 \\
\hline Vinyl or wood/vinyl hybrid & 0.90 & 0.54 & 0.48 \\
\hline
\end{tabular}


Source: (Carmody et al., 2000)

\subsection{Position of the sun}

The sun position in the sky always changes seasonally and affects the availability of daylight. Position of the sun is the true altitude and azimuth of the sun based on the geographic location. The day became brighter when the sun angle is higher. The best orientation of the buildings can be determined by the sun's angle. The movement of the sun from east to west and the angle of the sun to the opening affect the amount of daylight penetration into the building.

\subsection{Description of Case Study}

The study comprises of three case studies in order to distinguish the difference of daylighting performance through selected window. Table 3 indicates the parameter of every case study. In each case study, only one type of window in the living room was concentrated, the other windows were covered with black cloth as to make sure that the measured illumination level only penetrated through the selected window. In order to analyze daylight performance, only windows facing south were chosen to avoid direct light transmission to the interior, which resulting to unwanted desirable effect such as glare and thermal discomfort.

Table 3: Parameter of The Case Study

\begin{tabular}{|l|c|c|c|}
\hline & Case Study 1 & Case Study 2 & Case Study 3 \\
\hline Window type & asement window & d louver window & ted louver window \\
\hline Window head height above floor surface & $21 \mathrm{~T} 0 \mathrm{~mm}$ & $2325 \mathrm{~mm}$ & $21 \mathrm{T0} \mathrm{mm}$ \\
\hline Glass type & Obscure glass & Clear glass & Tinted glass \\
\hline Thickness of the glass & $3 \mathrm{~mm}$ & $3 \mathrm{~mm}$ & $3 \mathrm{~mm}$ \\
\hline Visible Transmittance (VT) & 0.18 & 0.64 & 0.56 \\
\hline Solar Heat Gain Coefficient (SHGC) & $0.5 \mathrm{~T}$ & 0.63 & 0.65 \\
\hline U-value & 0.90 & 0.90 & 1.25 \\
\hline Size of the window & $1830 \square 1250 \mathrm{~mm}$ & $122 \mathrm{~T}$ 口 $625 \mathrm{~mm}$ & $1830 \square 1250 \mathrm{~mm}$ \\
\hline Point numbered & A1-A4 & B1-B6 & C1-C5 \\
\hline
\end{tabular}

\subsection{Malaysia geographic location and climate conditions}

Malaysia is located in the south east part of Asia and lies in a geographic coordinate of $2^{\circ} 30^{\prime}$ North latitude and $112^{\circ} 30^{\prime}$ East longitude. Malaysia receives a lot of daylight throughout the year. It is the result from its coordinate of latitude and longitude. Fadzil (2003 recommended that daylighting should be utilized in the built environment particularly in daylight hours, and 
particularly in Malaysia where daylight is available in abundance and for free. Besides that, according to Zain-Ahmed (2000 the sky condition in Malaysia is intermediate or average which 85.T percent of the time the sky is cloudy and 14.0 percent is overcast.

\subsection{Methodology}

These studies were conducted in three different houses which focused only the living room. These three houses represented three different types of window, casement with obscure glass window (CWOGW, fixed louver with clear glass window (FLWCGW and adjusted louver with tintedglass window (ALWTGW . These types of windows were selected to provide analysis on the penetrations of the daylighting into the area. The areas were studied by using straight line points along the central axis of the window and Chroma Meter CL-200 Konica Minolta were used to collect all the illumination level data. The points are $1 \mathrm{~m}$ apart from each other and the data were taken at $0.75 \mathrm{~m}$ from floor which represents the height of working plane as shown in Figures 1,2 and 3

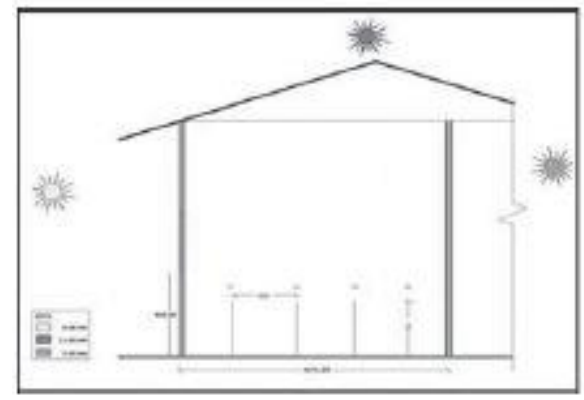

Figure 1: Section of The Room Indicating Measuring Points Location (Casement Window with Coated Glazing

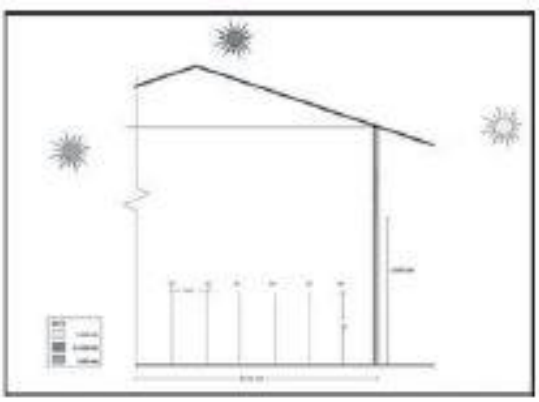

Figure 2: Section of The Room Indicating MeasuringPointsLocation(Fixed Louver Glass Window)

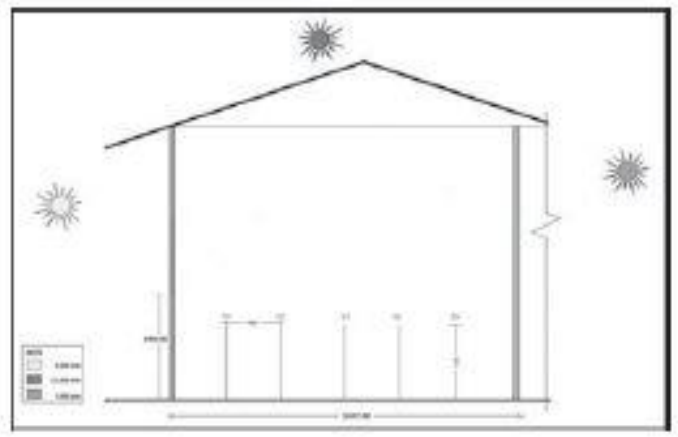

Figure3: Section of The Room Indicating Measuring PointsLocation (Louver Tempered Tinted Glass Window) 
. The height is assumed to be the level of doing normal activity. The readings were recorded at three separate periods of a day $(9.00 \mathrm{am}, 12.00$ noon and $5.00 \mathrm{pm}$ in relations to the rising and movement of the sun. The internal and external illuminance readings were taken simultaneously and the condition of the outdoor climate was also recorded. After that, some interviews were carried out in order know the occupant's perception on the penetration of daylight.

\subsection{Results and Discussions}

Different types of window had been selected to locate different performance of window fenestration. Analysis was made to evaluate the depth of the daylight penetration through the selected types of window. The results shown in Tables 4 to 6 illustrate, respectively, the illuminance values (lux at $9.00 \mathrm{am}, 12.00$ noon and $5.00 \mathrm{pm}$ for every selected windows. From these tables it indicates that ALWTGW transmit higher illuminance level than CWOGW and FLWCGW at the point $1 \mathrm{~m}$ adjacent to the window.

Table 2: Illuminance Values for Casement With Obscure Glass Window (CWOGW)

\begin{tabular}{|c|c|c|c|}
\hline Point & 9.00 am (lux) & 12.00noon(lux) & 5.00 pm (Iux) \\
\hline $\mathrm{A} 1$ & 196.9 & 189.2 & 153.4 \\
\hline A2 & $18 \mathrm{~T} .4$ & 130.9 & 121.0 \\
\hline A3 & 160.0 & 92.9 & 15.9 \\
\hline A4 & 123.5 & T3.6 & 14.6 \\
\hline External Illuminance & $241 \mathrm{~T}$ & 2015 & 690.T \\
\hline Weather & Good & Good & Good \\
\hline Sky Condition & Overcast & Overcast & Overcast \\
\hline
\end{tabular}

Table 3: Illuminance Values for Fixed Louver With Clear Glass Window (FLWCGW)

\begin{tabular}{|c|c|c|c|}
\hline Point & $9.00 \mathrm{am}$ (lux) & $\mathbf{1 2 . 0 0}$ noon (lux) & $\mathbf{5 . 0 0 ~ p m ~ ( l u x ) ~}$ \\
\hline B1 & 8.4 & 5.4 & 3.2 \\
\hline B2 & 14.6 & $11 . T$ & 5.2 \\
\hline B3 & 25.4 & 15.3 & 9.6 \\
\hline B4 & 38.4 & $18 . T$ & 10.4 \\
\hline B5 & 60.3 & 24.5 & 12.3 \\
\hline B6 & T4.1 & 36.2 & 18.3 \\
\hline External Illuminance & $258 T$ & 2108 & 1238 \\
\hline Weather & Good & Good & Good \\
\hline Sky Condition & Overcast & Overcast & Overcast \\
\hline
\end{tabular}


Table 4: Illuminance Values for Adjusted Louver With Tinted Glass Window (ALWTGW)

\begin{tabular}{|c|c|c|c|}
\hline Point & 9.00 am (lux) & 12.00 noon (lux) & $\mathbf{5 . 0 0 ~ p m ~ ( l u x ) ~}$ \\
\hline C1 & 424.6 & 264.5 & 295.4 \\
\hline C2 & $14 T .6$ & 105.1 & $99 . T$ \\
\hline C3 & 88.8 & $49 . T$ & $41 . T$ \\
\hline C4 & 66.8 & 32.9 & 31.3 \\
\hline C5 & 61.1 & 30.1 & 29.6 \\
\hline External Illuminance & $2 \mathrm{~T} 42$ & 1502 & 1048 \\
\hline Weather & Good & Good & Good \\
\hline Sky Condition & Overcast & Overcast & Overcast \\
\hline
\end{tabular}

As the selected houses were located at the same orientation position, the areas tend to receive maximum daylight during 9.00 am compared to $5.00 \mathrm{pm}$ (as shown in Figure 4 to 6 From Figure 4, it is clearly shown that the highest daylight transmittance was at the point near to the window ( $A 1$ and slightly decreases at $A 2$ but dropped significantly at $A 3$ ( $3 \mathrm{~m}$ from the window especially during 12.00 noon $(92.9 \mathrm{~lx}$ and $5.00 \mathrm{pm}$ (15.9 Ix. Although some of the areas received less natural light during 12.00 noon and $5.00 \mathrm{pm}$, occupants indicate that within the distance of $4 \mathrm{~m}$ from the window, CWOGW still allowed sufficient natural light for them to accomplish general task at living room and able to maintain occupant's comfort and productivity. It happens because this glass transmits most of the daylight and only transmits $5 \mathrm{~T} \%$ of solar heat to the interior. Thus, it helps to block unwanted heat gain entering the space and at the sametime can save on cooling costs.

Figure 5 represents the illuminance level along lines B1 to B6 for FLWCGW. Findings revealed that this window does not allow sufficient daylight transmittance due to its position and size of fenestration. From these figures, it is found that the maximum illuminance that is able to penetrate into the interior is only T4.1 lx during $9.00 \mathrm{am}$ at point B6. Then the illuminance level decreases significantly as the distance from the window increases. Less amount of light will affect visual comfort and difficult for occupants to carry out general activities. According to Lewis, the higher the window head is from the floor, the deeper the daylight can penetrate into the whole area. In this case study, even though the window head height is over $2 \mathrm{~m}$ above floor surface, but the window height and width are too small, thus it reduces the quantity of natural light that penetrates into the interior and produces nonuniformity of lighting. As a result this area tends to look gloomy and required supplementary artificial lighting. Besides that, the window area also affects the quantity of natural daylight penetrate into this living room. By using clear glass, it generally should permit highest daylight transmission $(64 \%$ of visible light is transmitted to the interior but the window area which only $122 \mathrm{~T}$ x $625 \mathrm{~mm}$ influence less daylight penetration.

Referring to Figure 6, ALWTGW allowed higher illumination level than CWOGW and FLCGW especially at the points placed at the distance of $1 \mathrm{~m}$ from window $-424.6 \mathrm{~lx}, 264.5 \mathrm{~lx}$ and $295.4 \mathrm{~lx}$ for $9.00 \mathrm{am}, 12.00$ noon and $5.00 \mathrm{pm}$, respectively. Generous illumination values 
were achieved by ALWTGW due to the properties of the glass window itself which able to admit $56 \%$ of daylight to improve indoor daylighting by limiting glare and redirect diffuse light. The capacity of this glass to admit daylight is $56 \%$. However, readings taken at the distance of $2 \mathrm{~m}$ from the window show that the level of illuminance dropped significantly to14T.6 $\mathrm{Ix}(9.00$ am , $105.1 \mathrm{~lx}$ (12.00 noon and $99.5 \mathrm{~lx}$ (5.00 pm. As the distance of the points of reading increased, the illumination level dropped gradually.

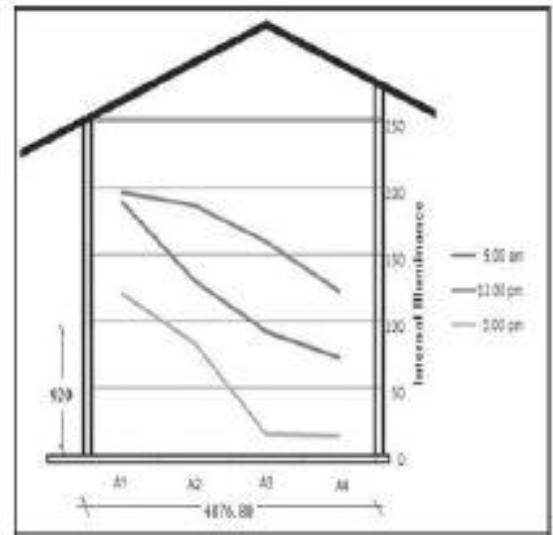

Figure4: Internal IlluminanceatPoint A1 - A4

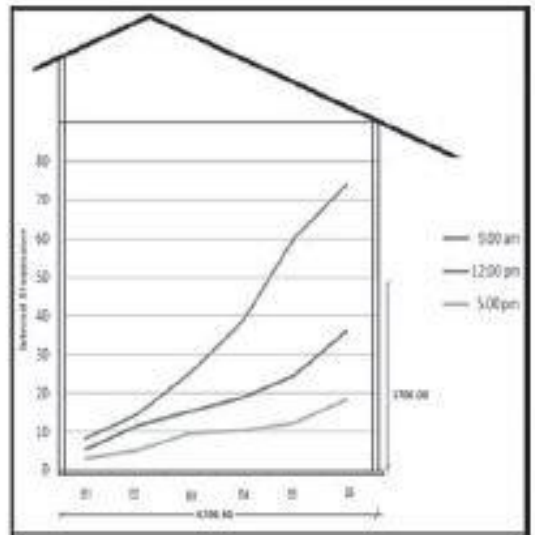

Figure 5: Internal IlluminanceatPoint B1 - B6

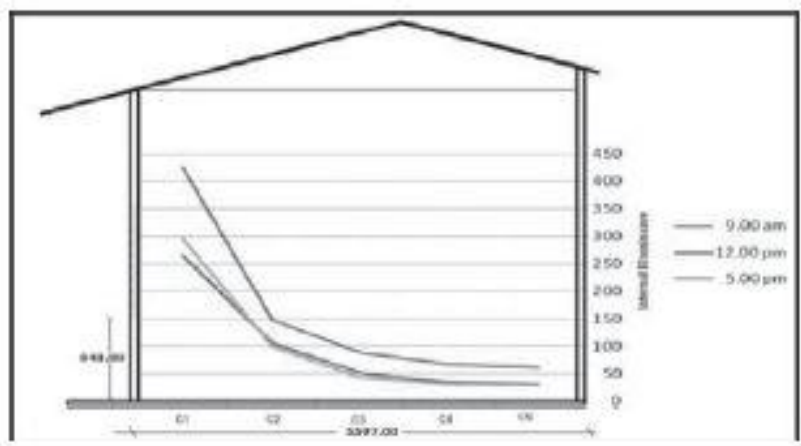

Figure 6: Internal Illuminance at Point C1 - C5

\subsection{Conclusion}

This paper examined typical windows widely used in residential building in Malaysia with the intention of identifying their daylighting performance and evaluating the quantity of the daylighting entering into the interior. It can be concluded that casement window and louver window with clear glass, obscure glass or tinted glass are commonly used as residential 
fenestration in Malaysia. The analysis of daylight penetration through these tree types of windows showed that Casement with Obscure Glass Window (VT=0.18, SHGC $=0.5 \mathrm{~T}, \mathrm{U}$ Value $=0.90$ is able to distribute enough daylight into the roomand maintain occupant's visual comfort. While for Fixed Louver with Clear Glass Window (VT=0.64, SHGC $=0.63$, U-Value $=0.90$ , the amount of the highest illumination level that was able to be transmitted was only T4.1 Ix. Even though this glass has higher value of visual transmittance but the size of the window has more impact on the amount of daylight penetration into the area. Adjustable Louver with Tinted Glass Window (VT=0.56, SHGC $=0.65$, U-Value $=1.25$ could give enough daylight until $3 \mathrm{~m}$. For window which daylighting is desirable CWWCG and LTTGW are the best choice because they are able to admit necessary daylight and able to reduce glare from the bright outdoor and thus reducing the amount of solar energy transmitted through the glass. Therefore, to increase daylighting performance, the room should have proper design technique on the size and position of the windows, and types of suitable glazing for suitable function of building. Therefore it will help in fully using the natural light by allowing uniform distribution of the total illuminance value to the entire room. From the research, it is shown that type of glazing and window gives major significance on the performance of natural light and thermal performance of adjacent space.

\section{Acknowledgement}

The author is very grateful to the owners of the houses concerned for the cooperation given during the data collection stage. Special thanks is also dedicated to Assoc. Prof. Zarina Yasmin Hanur Harith who keeps on giving support and sharing her knowledge for completing this research.

\section{References}

A. Zain-Ahmed, K.Spian, Z.Zainol Abidin and M.Y.HOthman, (2000). The AvailabilityofDaylightFrom TropicalSkiesCaseStudyofMalaysia. Kuala Lumpur: Universiti Kebangsaan Malaysia, Elsevier Science Ltd.

Abu Nur Mohammad Shahriar and Mohammad Abdul Mohit. (2006), Estimating Depthof Daylight Zone and PSALIforSide LitOfficeSpaces Using the CIE Standard General Sky. Kuala Lumpur: Elsevier Ltd.

D.H.W.Li, S.L.Wong, C.L.Tsangand GaryH.W.Cheung, (2006 . A Study of the Daylighting Performance and Energy Use in Heavily Obstructed Residential Building via Computer Simulation Techniques. Hong Kong: Elsevier Ltd.

Illuminating Engineering Society of North America (IESNA), (1993). American National Standard Practice for Office Lighting. USA: Illuminating Engineering Society.

J. Owen Lewis, (2000). Developing a Low Energy Architecture for Europe. Cambridge, United Kingdom: Proceedings of PLEA 2000

John Carmody, Stephen Selkowitz, Darius Arasteh and Lisa Heschong, (2000).ResidentialWindows: Guideto NewTechnologiesandEnergy Performance. New York: W.W Norton \& Company

Norhati Ibrahim and A.Zain-Ahmed, (2007). Daylight Availability in an Office Interior due to Various 
Syed Husin, S.N. \& Hanur Harith, Z.Y. / Asian Journal of Environment-Behaviour Studies (ajE-Bs), 3(6) Jan / Feb 2018 (p. 169-178)

Fenestration Options, Greece: $2^{\text {nd }}$ PALENC Conference and $218^{\text {th }}$ AIC Conference on Building Low Energy Cooling and Advanced Ventilation Technologies in The $21^{\text {st }}$ Century.

Sharifah Fairuz Syed Fadzil and Sheau-Jiunn Sia, (2004). Sunlight Control and Daylight Distribution Analysis : The KomtarCase Study. Malaysia: University Science Malaysia Publication.

Standards and Industrial Research Institute of Malaysia (SIRIM), (2006). Energy towards Sustainable Energy Sources and Consumption: Standard and Quality News. Malaysia: SIRIM Berhad. 